\title{
Big Data and Dynamic Capabilities: A Bibliometric Analysis and Systematic Literature Review
}

\author{
Riccardo Rialti \\ DISEI - Dipartimento di Scienze per l'Economia e l'Impresa, \\ Università degli Studi di Firenze, Firenze, Italy
}

Giacomo Marzi

Lincoln International Business School, Department of Strategy and Enterprise, University of Lincoln, Lincoln, UK

\section{Cristiano Ciappei}

DISEI - Dipartimento di Scienze per l'Economia e l'Impresa,

Università degli Studi di Firenze, Firenze, Italy, and

\author{
Donatella Busso
}

Dipartimento di Management, Universita degli Studi di Torino, Torino, Italy

\section{Published in Management Decision}

FULL TEXT (DOI): https://doi.org/10.1108/MD-07-2018-0821

\begin{abstract}
Purpose-Recently, several manuscripts about the effects of big data on organizations used dynamic capabilities as their main theoretical approach. However, these manuscripts still lack systematization. Consequently, this paper aims to systematize the literature on big data and dynamic capabilities.

Design/methodology/approach-A bibliometric analysis was performed on 170 manuscripts extracted from the Clarivate Analytics Web of Science Core Collection database. The bibliometric analysis was integrated with a literature review.

Findings-The bibliometric analysis revealed four clusters of papers on big data and dynamic capabilities: big data and supply chain management, knowledge management, decision making, business process management and big data analytics (BDA). The systematic literature review helped to clarify each clusters' content.

Originality/value - To the authors' best knowledge, minimal attention has been paid to systematizing the literature on big data and dynamic capabilities.
\end{abstract}

Keywords: Bibliometric Analysis, Big Data, Big Data Analytics, Dynamic Capabilities, Performance, Systematic Literature Review.

Paper type: Research Paper 


\section{Introduction}

Big data has dramatically affected the traditional ways of running a business in the $21^{\text {st }}$ century (Chen et al., 2012; McAfee and Brynjolfsson, 2012). In the current technological era, big data managers have an almost infinite amount of detailed information at their disposal (Erevelles et al., 2016). Therefore, it is widely assumed that big data will allow managers to be increasingly informed on the state of internal operations, supply chain processes, workforce's performances, and the consumers' behavioural patterns (Bresciani et al., 2017). Management decisionmaking processes are simultaneously evolved and, as such, managers get the ability to decide upon the most suitable strategy to implement according to the newly available information (Chen et al., 2012).

In the light of the emerging potential of big data, it is evident that there is a requirement of studies about such systems and related organizational capabilities. It is needed to decodify and transform these datasets into insights, management decisions, and organizational performances (Labrinidis and Jagadish, 2012). Thus, scholars started to point out how big data are such complex datasets, formed by heterogeneous data, that may be analysed only using Big Data Analytics (BDA) systems (Rialti et al., 2018). Only information systems capable of processing different kind of data formats simultaneously may ensure that the necessary information flows in big data era (Vera-Baquero et al., 2016). On the other hand, as organization-wide capabilities are necessary to make everyone use complex technological systems, BDA capabilities have started receiving attention simultaneously from pertinent literature (Chen et al., 2012). It has emerged how organizations should foster the development of internal technical, managerial and personnel capabilities in order to exploit the big data and properly use BDA systems (Akter et al., 2016).

In case an organization is capable of implementing proper systems and develop the right capabilities, the true potential of big data availability may then emerge. Accordingly, big data were seen to be linked to increased organizational performances in terms of agility, flexibility, and ambidexterity (Rialti et al., 2018). With this, the apparent impact of big data on dynamism started. Specifically, an organization may be able to scan the environment constantly and obtain a competitive edge with such capabilities. Consequently, big data, BDA systems and BDA capabilities were observed to influence value creation processes (Wamba et al., 2017).

Several different streams from different literatures have explored how organizations can exploit big data to create value. Researchers dealing with informatics and information systems were the first to explore the importance of big data (Chen et al., 2014). Obviously, theoretical approaches used by different scholars were related to the streams of literatures their papers were focussed on. Appropriately, in terms of managerial literature, scholars have mostly used dynamic capabilities - even if sometimes in conjunction with other theories like IT business value or Knowledge Based View (KBV) - as the principal theoretical approach to understand how big data are affecting organizations (Côrte-Real et al., 2017).

Dynamic capabilities represent a suitable approach to study the effect of information systems or their specific capabilities on the organizations (Contractor et al., 2016). The utilisation of BDA capable systems is frequently linked to common processes and routines that may be used to solve different data-related problems (Wamba and Mishra, 2016). The adaptable BDA systems are usable in different situations and may provide a competitive edge during environmental turbulence (Akter et al., 2016). Similarly, BDA capabilities are a set of capabilities that may help an organization to adapt an existing resource base (in this case data) to address different information needs emerging in different situation (Rialti et al., 2018). As both these considerations are coherent with dynamic capabilities theory, it emerges that dynamic capabilities are the most used approach in research about big data and performance (Wamba et al., 2017). 
In spite of this growing interest in big data, dynamic capabilities, and organizational performances, these manuscripts lack a proper systematization. Consequently, it is clear that there is necessity of mapping and systematizing existing literature (Braganza et al., 2017). To do this, the authors have performed a bibliometric analysis to map the knowledge concerning this stream of research and they have systematically reviewed literature to explore content of the most relevant papers (Caputo et al., 2018).

This paper is structured as follows: the following paragraph analyses the importance of big data and BDA systems and their capabilities to organizations, and the contributions of dynamic capabilities in this stream of literature; next, the methodological procedure is described; then, the results of the bibliometric analysis and the systematic literature review are presented. Finally, the authors present their suggestions for future research.

\section{Theoretical Background}

\subsection{Big Data: The Revolution has Arrived}

According to the seminal research by McAfee and Brynjolfsson (2012), "smart leaders across industries will see using big data for what it is: a management revolution" (2012, p. 5). Several years later, the magnitude of the impact of big data across the management world is clearly visible to everyone involved with big data. While information has always been identified as one of the most important value-creating factors for any organization, big data characteristics have brought information value-creation potential to an unprecedented level (El-Kassar and Singh, 2018).

Big data differs from traditional large datasets in terms of its Volume, Velocity, Variety, Veracity, Value, Variability, and Visualization - a.k.a. 'Seven Vs of Big Data' (Mishra et al., 2017). Volume refers to the sheer dimensions of the typology of datasets (McAfee and Brynjolfsson, 2012). Indeed, big data's dimensions frequently exceed the terabyte (Mishra et al., 2017). Velocity of big data is the "rate at which data are generated and the speed at which it should be analysed and acted upon" (Gandomi and Haider, 2015, p.138). Variety is related to the "heterogeneous sources of big data (i.e. sensors embedded in machines, consumers' activities on social media, B2C or B2B digital interactions, etc.) and the consequent heterogeneous formats that the files composing big data may assume" (Rialti et al., 2018, p.7). Veracity is related to the necessary degree of trustworthiness that the sources of big data must possess (Mishra et al., 2017). Value is linked to the economic value that may be generated by an organization due to processes and technologies that analyze big data (Xuemie, 2017). Variability refers to the possible variations in data flow rate, processing, and data sources (Wamba and Mishra, 2017). Finally, Visualization concerns the possibility for data analysts to get visual insights as an output of big data analysis (Mishra et al., 2017).

As it is deducible from big data's characteristics, the extraction of insights from these datasets poses unprecedented challenges to organizations. Big data are indeed so large and complex datasets that cannot be processed using traditional database software (Maniyka et al., 2011). Data lakes, NoSQL data models, schema-less data retrieval, machine learning and other tools based on artificial intelligence paradigms are necessary to collect, store, and analyze big data. As such, organizations may define $a d$-hoc big data analytics processes at the following stages: data acquisition, cleansing, integration, modeling, and interpretation (Labrinidis and Jagadish, 2012).

Coherently, organizations should focus on developing BDA systems capable of supporting such processes. Thus, BDA systems should not only be capable of collecting data, but also clearing it from unworthy components (i.e. spam messages or messages without any useful content), modeling data, and obtaining information that could generate competitive advantages and economic value (Prescott, 2014). The implementation of these systems is not 
without their challenges. First of all, BDA systems usually need extremely large networked hardware's architecture, and need to rely on cloud storage and computing, and require extremely fast internet connections (Gandomi and Haider, 2015). Infrastructural and technological complexity is the first problem. Second, very frequently, such systems are built around such complex infrastructures and architectures, or depend on extremely complicated computer-science analytics methods, that managers and employees may reject the implementation of these systems (Xuemie, 2017), as they may not understand how such systems work. Specifically, managers and employees may resist this change and oppose the implementation of automatic systems capable of complementing human intervention in decision making. Thus, for modern organizations, the importance of simultaneously fostering the development of technical, managerial and personnel big data analytic (BDA) related capabilities emerged (LaValle et al., 2011). Specifically, all the people who will have to deal with BDA in the organization, should be capable of at least partially understanding the complexity of the infrastructure, the main methodologies of analysis, the potential effects on existing processes, and the potential outcomes of BDA (Côrte-Real et al., 2017). To do so, the culture of the whole organization must be changed to accept BDA capable systems and/or processes (Rialti et al., 2018). Anyway, if managers and employees will develop enough BDA capabilities to get accustomed to big data and BDA systems, it will be possible to observe that the whole organization could become characterized by the so-called 'big data culture' and start harvesting big data benefits (Frisk and Bannister, 2017).

Notwithstanding all potential difficulties, once in place, big data systems tend to have positive outcomes (Akter et al., 2016). Managers may indeed make decisions according to the insights that they gather from BDA systems, thus, improving the accuracy of their decisions (Santoro et al., 2017). Big data can offer managers the possibility of knowing their consumers better than ever. With big data, it is possible to predict individual consumer's behavior and propose tailored offerings in terms of prices (Erevelles et al., 2016). Big data can also dramatically affect organization's internal operation efficiency and BDA may prove extremely useful for the control of performance of business processes (Del Giudice, 2016; Acharya et al., 2018). Indeed, BDA systems may allow managers to identify bottlenecks in the production processes, inefficiencies in machine usage and wasting of resources. BDA systems may also be linked to better workforce utilization and may permit managers to better monitor the performance of each employee. BDA systems may also positively impact an organization's ability to pursue collaborations with partners. Particularly, BDA systems may improve knowledge flow and facilitate sharing between partners as they are frequently built around jointly-developed hardware architectures (Vera-Baquero et al., 2016). BDA may play a role in fostering the organizational capability of identifying and seizing new opportunities. With the newly extracted information, BDA capable systems can improve organizational exploitation and exploration capabilities and, consequently, ambidexterity (Rialti et al., 2018). In short, big data is progressively influencing organizations' competitiveness.

As a consequence of the impact of big data on organizations, pertinent literature has stressed that these may be positively linked to better performance (Gunasekaran et al., 2018). In particular, it has emerged that big data and BDA systems and capabilities, both impact organizational performance metrics (i.e. workforce utilization, supply chain efficiency, production processes efficiency) and financial performance metrics, which may improve over the time (McAfee and Brynjolfsson, 2012). However, as previously assessed, all of the positive effects of big data derive from the organizational decision and the organization's acceptance of big data. Organizational processes, such as resource allocation, orchestration, and exploitation, thus, play an important role in the organization's ability to reap the benefits of big data (Teece, 2009). From this perspective, dynamic capabilities have been frequently involved in research exploring the importance of big data for organizations (Wamba et al., 2017). 


\subsection{BDA, Dynamic Capabilities, and Performance}

The notion of dynamic capabilities was originally coined by Teece, Pisano, and Shuen in 1997. According to their seminal manuscript, the essence of the dynamic capabilities concept lies in the organization's "ability to integrate, build, and reconfigure internal and external competencies to address rapidly-changing environments" (Teece et al., 1997, pp.516). The 'dynamic capabilities' are related to organization-wide ability to adequately and timely adapt to the changing environment by reconfiguring internal or external processes and resources, with the existing competencies (Eisenhardt and Martin, 2000; Gaur et al., 2014).

While it may appear that dynamic capabilities definitions link organizations' reactions to improvisation (i.e. it may seem that organizations simply respond to changes by spontaneous re-organization of resources using existing skills), actually dynamic capabilities derive from the existence of "identifiable and specific routines" (Eisenhardt and Martin, 2000, p. 1107). Some organizational routines and processes are capable of diffusing the best practices within an organization (Hwang and Gaur, 2009). In this vein, Eisenhardt and Martin (2000) observed how organizational routines or processes may be broken down into smaller routines, or small processes, which are the 'bricks' for forming a completely new routine or process. Consequently, once an organization has implemented the original routine or process, formed by several bricks, these bricks may be reassembled to form a new routine or process necessary to survive and succeed in the mutated environment (Nuruzzaman et al., 2018). This phenomenon is linked to the assumed importance of expertise conservation within an organization, and to the fact that the same knowledge base may be used in more than one situation (Popli et al., 2017). Using this, it is possible to assess whether an organization has developed dynamic capabilities and it has become capable of adapting to change by exploiting existing resources, processes, knowledge and existing routines deriving from the continuous repetition of a similar action (Gaur et al., 2014). Thus, it emerges that the dynamic capabilities theory extends to both, resource-based view (RBV) and KBV (Côrte-Real et al., 2017). Dynamic capabilities, in fact, posit that the competitive advantage is not only driven from organization's ability to reconfigure resources, but also from the ability to re-arrange them purposively (and timely) based on existing knowledge (Gaur et al., 2014; Popli et al., 2017).

In the big data era, dynamic capabilities have frequently been adopted by scholars as a theoretical perspective to unpack how big data or BDA systems and capabilities affect an organization (Wamba et al., 2017). To understand the effects of big data, scholars need to focus simultaneously on three perspectives, namely: (1) data as resources, (2) recurrent routines, processes and capabilities to analyse big data, and (3) the management of knowledge emerging from these data (Ferraris et al., 2018). First, scholars should always consider that big data are an information resource characterized by a multiple usability potential, i.e. big data may be utilized more than once to get different information to solve diverse problems (Erevelles et al., 2016). Second, the analysis of big data requires routines, processes and capabilities to turn such data into meaningful insights (Côrte-Real et al., 2017), where previous expertise from analysts and managers can also be helpful in increasing the efficiency of big data analysis (Zeng \& Khan, 2018). Third, as the analysis of such datasets may generate huge knowledge flows that scholars always have to consider for proper management of the knowledge emerging from big data to create value (Ferraris et al., 2018). Accordingly, it emerges that the singular use of RBV or KBV would not be sufficient to completely interpret how big data and BDA system and capabilities create value. For instance, when a scholar is using only RBV, he/she will only observe how big data can create value for the new information at managers' disposition. By doing so, he/she will be neglecting the importance of routines in big data analysis. Similarly, the exclusive use of KBV will merely allow a scholar to observe how knowledge flows deriving from big data may influence decision making processes, but it won't allow him/her to consider 
big data as an information-related resource that can be to solve more than one problem. Contrarily, the use of dynamic capabilities theory will allow a researcher to unpack the outcome of big data by considering simultaneously how existing routines to analyze data may allow multiple use of such datasets and to diffuse knowledge to all the people in the organization.

In the light of this, it is understandable why scholars have used dynamic capabilities to interpret the ways in which BDA systems and capabilities generate competitive advantages. Scholars have used dynamic capabilities to explain why the use of BDA systems is based on re-application of routines, which are fundamental for generating new information to overcome rivals (Braganza et al., 2017). Indeed, scholars have observed that the development of organization-wide BDA capabilities may trigger BDA systems' users into learning new routines to analyze different kinds of data over time. Such routines may be used by users in different analytical processes that may be vital to run BDA systems during a change (Rialti et al., 2018). It emerges that BDA systems equate to constant knowledge generation and diffusion, through which they allow managers and analysts to identify good opportunities and to reject not-profitable ones. Secondly, dynamic capabilities have been used as a theoretical approach to observe how big data can affect marketing strategies (Khan and Vorley, 2017). This phenomenon has been deemed to be related to the potential of BDA systems to explore the behavioral patterns of consumers and, therefore, to foster the creation of customized marketing strategies in a timely manner (Erevelles et al., 2016). Thirdly, Wamba et al. (2017) have observed that the process oriented dynamic capabilities and BDA may influence both organizational and financial performances. In particular, they have observed that the possibility for a process to adapt to changing situations may be influenced by the diffusion of BDA systems within an organization. This is coherent to the fact that BDA information decision makers may predict what is going to change in the environment and accordingly modify processes. Similarly, Sivarajah et al. (2017) assessed BDA systems capacity to adapt to different kinds of data and to the evolving environments and deduced that this may generate competitive advantages.

According to pertinent literature, there is still a need to properly understand the structure and the organization of existing literature concerning big data, dynamic capabilities and performance (Braganza et al., 2017; Côrte-Real et al., 2017). Indeed, while several manuscripts have used the bibliometric method to explore other streams of big data related literature (Mishra et al., 2017), scant attention has been paid to this specific topic.

\section{Methodology}

Bibliometric methods have been widely used to provide comprehensive maps of the knowledge structure in a given streams of literature. However, as the authors are investigating an emerging field of research, to perform an accurate analysis of the literature, both bibliometric analysis and systematic literature review techniques are used (Caputo et al., 2018; Marzi et al., 2018). A bibliometric analysis was conducted first, followed by a systematic literature review of the bibliometric results. The bibliometric analysis is based specifically on the 'visualization of similarities' (VOS) technique (Van Eck and Waltman, 2010). For the systematic literature review, the authors followed the procedure proposed by Tranfield et al. (2003). The entire process consisted of six steps.

The first step is the search of a wide research query on the Clarivate Analytics Web of Science Core Collection database, which offers the most valuable and high-impact collection of data and is recognized as the most updated and reliable database for bibliometric studies (Falagas et al., 2008). The process of selecting a research query began with a literature review of the cornerstone manuscripts about BDA capable systems for management, using dynamic 
capabilities as the main underlying theory to grasp all of the terms used to describe the phenomena that the authors wanted to analyse (i.e. Akter et al., 2016; Wamba et al., 2017). After several iterations to define a broad research query, the final query was:

\section{$T S=((" b i g$ data" OR "big data analytics") AND ("dynamic capabilities" OR performance*) AND (organization* OR firm* OR business* OR enterprise*))}

The 'TS' operator performed a full search of the selected terms in titles, abstracts, and keywords. The search was limited to "articles, books, book chapters, book reviews, early access articles, and editorial material", as document type. A ten-year cross-section - 2007 to 2017 was the considered as the timespan. A preliminary dataset of 375 entries was generated by the query.

As previously assessed, research data were extracted only from Web of Science Core Collection database. In fact, Web of Science Core Collection, among the existing databases such as Scopus or EBSCO, has been frequently recognized as the database which includes most of the papers published in reputable journals over the time, including the majority of papers recently accepted by journals (Marzi et al., 2018). Additionally, if the same query is used and the same search parameters are set, previous research has pointed out that the use of Web of Science Core Collection usually provides less out of topic/aim papers that should be excluded from the analysis. Unlike Scopus and EBSCO, the Web of Science Core Collection doesn't include papers written in magazines or non-scientific journals (Caputo et al., 2018). This phenomenon also proved to be true in this research. In fact, authors also manually checked Scopus and EBSCO databases and did not find any paper was not already included in the Web of Science Core Collection database results.

The second step was devoted to defining the inclusion criteria for the documents to be utilised in this study, and then to do the manual analysis and selection of each document. The authors decided to base the selection on three inclusion criteria, two of them related with the definition of big data and one related with dynamic capabilities. The first criteria were the most generally accepted definition of big data as "datasets whose size is beyond the ability of a typical database software tools to capture, store, manage and analyse" (Manyika et al., 2011, p.1). The second criteria were the definition of big data as datasets simultaneously characterized by Volume, Velocity and Variety, a.k.a. the original 3Vs of Big Data (McAfee and Brynjolfsson, 2012). Only the original 3Vs of big data were selected since the additional $4 \mathrm{Vs}$ (Veracity, Value, Variability, and Visualization) were identified as characteristics of big data by scholars only in recent years (Wamba and Mishra, 2017). Considering the 3 Vs was, therefore, an appropriate parameter as it was allowing to evaluate whether a research was effectively outlining big data using a widely-accepted definition, without preventing older research manuscripts from being included from the dataset. In the third criteria authors excluded manuscripts that did not consider dynamic capabilities as a research perspective and manuscripts not belonging to management-related literature. After applying these three inclusion criteria, the final dataset consisted 170 entries.

The third step consisted of critically reading the 170 selected manuscripts by all four authors to obtain a working knowledge of how BDA are linked to dynamic capabilities and firm performances (Wamba et al., 2017).

Subsequently, the fourth step consisted of the initial part of the bibliometric analysis. Specifically, the authors performed an analysis using activity indicators to gather data on the volume of research, allowing us to observe the quantitative evolution of the literature.

The fifth step involved the proper bibliometric analysis. Software tool VOSviewer 1.6.5 was used for the aggregation of the manuscripts, with bibliographic coupling as the aggregation mechanism (Van Eck and Waltman, 2010). Bibliographic coupling occurs when two works 
cite a common third work in their references; consequently, two documents are bibliographically coupled when they cite one or more documents in common. The output of VOSviewer is a map in which the items' distance can be interpreted as an indication of the relatedness of the terms. The smaller the distance between the terms, the more strongly the terms are associated with each other. In addition, the cluster analysis highlights the knowledge base diversity in an aggregate way: if the manuscripts belong to the same cluster, it means that they are strongly linked together as a group based on their shared references. Thereby, a cluster represents a stream of research on a similarity basis. It is important to note that, on the map generated by VOSviewer, the manuscripts are presented in a convenient way to optimize their visualization; thus, the axes of the map do not have any meaning.

Finally, the sixth and last step involved systematic literature review process based on the results of VOS aggregation (Gaur and Kumar, 2018). Using the results of clustering found by VOSviewer, the authors analysed the most influential manuscripts inside the displayed clusters to highlight their main areas of focus.

\section{Bibliometric Analysis' Results}

In this section, the authors present the results of the aforementioned bibliometric analysis. The manuscripts' distribution over the years is presented in Table 1 and Figure 1.

Table 1 About Here

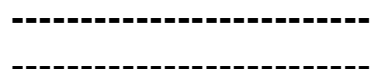

Figure 1 About Here

As shown, the majority of the selected manuscripts are 5-years old or less. Only 2 manuscripts have been published in 2012 and no manuscripts were published prior to this. While research has explored the importance of big data and BDA for management since the previous decade, only in the last five years, scholars started to explore this area using dynamic capabilities as a theoretical principle. According to the pattern revealed by the number of manuscripts published every year, the topic has yet to reach maturity. Indeed, the number of manuscripts on the topic are increasing every year.

In the following figure (Figure 2), the results of the VOS analysis are presented. Due to space-constrains, only the most influential manuscripts are shown and only the surname of the first author is included in the figure.

\section{Figure 2 About Here}

From our analysis of the 170 manuscripts, four clusters emerged. As selected by the query, all of the manuscripts included in the clusters use dynamic capabilities as a theoretical principle. The content of the four clusters will be explained in the next section.

\section{Systematic Literature Review}

Coherently with previous research containing both a bibliometric analysis and a systematic literature review, the final part of this research comprises of a systematic literature review. Yet, as it was not possible to do a complete review of all the 170 papers, only the ten most cited manuscripts from each cluster were reviewed (Caputo et al., 2018). 


\subsection{Red Cluster: Big Data, Dynamic Capabilities and Supply Chain Management}

This cluster aggregates manuscripts exploring the effects of big data on supply chain management, related dynamic capabilities and performance. Specifically, two groups of manuscripts emerged in this cluster. The first one deals with the implementation of BDA systems for supply chain management and the second is about the effect of big data and BDA on supply chain management performance.

In manuscripts about the implementation of BDA systems, Hazen et al. (2014), stressed that such systems' managers may gain visibility into supply chain processes, costs and revenues or flows of materials. Specifically, the implementation of BDA systems may allow managers to obtain accurate predictions about the future needs of productive factors. Yet, such benefits will emerge only in the case when BDA systems can rely on high quality data; thus, BDA systems should be capable of depurating raw data and filtering out not-useful information generating noise around useful data (Kwon et al. 2014; Kache and Seuring, 2017). In fact, two manuscripts point out how BDA systems may cause positive effects only if they analyse high quality data. Actually, the usage of low-quality data (or data not cleaned of unworthy information) has been found to give erroneous predictions leading to wrong decisions. This notwithstanding, the risks related with low quality data aren't related only with the quality of data analysed by BDA systems. Kwon et al. (2014) also stressed that people may refuse to properly use BDA systems. It was observed that people may oppose a technology when they are not able to understand the potential benefits. Both Kwon et al. (2014) and Chaffin et al. (2017) have assessed that conducting training programs to develop organization-wide BDA capabilities may help. On this topic, Lavertu (2016) has mentioned the importance of external help (i.e. specialized consultants) for any kind of organization wishing to implement BDA systems to support supply chain management.

In case, the organization, as a whole, is willing to accept BDA systems for supply chain management, they will be capable of improving supply chain performances.

The second group of manuscripts, as stressed by Gunasekaran et al. (2018), states that the BDA systems may dramatically affect supply chain management performances. Specifically, it became apparent that the routinization of processes derived from BDA systems usage may occupy a fundamental role in ensuring the adaptability of these processes to different situations. Hence, BDA systems may increase organizational dynamism, agility, and flexibility; particularly in the identification of problems and opportunities related to supply chain management (Chen et al., 2015). The new information derived from BDA systems is indeed related with organizations' capability to respond to changes that may disrupt supply chain (Dobrzykowsk et al., 2015). According to Papadopoulos et al. (2016), BDA processes showing their ability to improving supply chain management have also been related to increased sustainability. This phenomenon is linked to the fact that increased efficiency in supply chains may lead to a reduced quantity of waste. Tan et al. (2015), has highlighted the potential of information from BDA systems for supply chain innovation. Specifically, they have highlighted how such systems may allow the exchange of information with supply-chain partners, thus, enacting the emergence of new innovative idea.

\subsection{Green Cluster: BDA method for knowledge extraction}

The second cluster is formed by manuscripts about the importance of methods to extract knowledge from big data and exploit it. Lee (2017), for example, stressed that one of the biggest challenges of big data era is how to extract the needed information from big data and to turn it into exploitable new knowledge. Specifically, the aforementioned manuscript generically reviewed the most frequently used methods to solve big data related problems from the point of view of managers. In this vein, Zhou et al. (2014) focused on information technology 
methods that could make BDA systems work. As an example, it was emphasized that machine learning techniques are fundamental to analyse big data. Unsupervised statistical methods, allowing computers to automatically identify the most important insights, are in fact fundamental to process huge unstructured datasets such as big data. The importance for modern businesses to employee a specialized data analyst was also measured. Moving from these premises, Chen et al. (2014) and Li et al. (2016) explored how machine learning or artificial intelligence can be integrated into BDA systems. These manuscripts analysed the characteristics of BDA systems, apart from the importance of machine learning and artificial intelligence, show how BDA systems should also rely on cloud storage and cloud computing as the size of big data has made traditional hardware obsolete.

Tirunillai and Tellis (2014), instead, have focused on techniques that may be used to generate knowledge for marketers. Specifically, they investigated the potential of Latent Dirichlet Allocation (LDA), which is a machine learning based topic classification methodology, to extract insights about consumers' perceptions form UGCs (user generated contents). In a similar fashion, Fuchs et al. (2016) and Yang et al. (2014) have stressed the simultaneous importance of web crawlers/scrapers (i.e. applications to scrape web pages or social media to collect data) and content analysis methods to predict demands for a service. Finally, Kwon and Sim (2013) have identified the potential of classifications algorithms to extract meaningful knowledge from big data. In any case, this manuscript explains the importance of re-thinking traditional classification algorithms to the new dimensions of big data.

Hence, for BDA systems to be able to extract knowledge from big data and increase performance, it was observed that the BDA systems may represent a fundamental tool to extract knowledge, know more about consumers and competitors (Chen et al., 2013; Al Nuaimi et al., 2015).

\subsection{Blue Cluster: Big Data, Dynamic Capabilities, Decision Making and Performance}

Due to the knowledge that big data can contain, scholars paid significant attention to the impact of big data on decision making processes and subsequent organizational performances.

Fawcett and Waller (2014) and Tambe (2014) have recognized how BDA systems may generate predictions about future trends and that these predictions concerning sales, revenues and production requirements may be used by managers to formulate decisions about the future. Insights emerging from BDA can offer opportunities to managers to know more about their consumers in real-time. Erevelles et al. (2016) have examined how BDA can enhance marketing related strategic decision-making processes. This phenomenon has been verified as the information about consumers allows a manager to react dynamically to evolving consumer preferences. Similarly, Opresnik and Taisch's (2015) manuscripts showed how insights from BDA may influence the abilities of services providers to better tackle the needs of their consumers. Akter et al. (2016), Wamba et al. (2017) and Martin et al. (2017) pointed out how such insights may empower managers to take decisions that increase organizational efficiency in the supply and production processes. In fact, through predictive analytics it will be possible for managers to purchase just the minimum quantity of resources needed to cover the predicted request for products. Additionally, information from BDA system may also be fundamental to identify bottlenecks in production processes and reduce the wastage of resources.

Big data and BDA systems can, therefore, generate knowledge flows that are capable of changing the way managers think and act. Specifically, such flows may inform managers to take decisions about supply, production and sales. Managers may also be able to respond to sudden change as they may know almost exactly what is going to happen outside and, consequently, decide the best path for the organization to follow. In this perspective, CôrteReal et al. (2017) evidenced that big data availability and the implementation of BDA systems 
represents a potential source of information-driven competitive advantage. Tallon et al. (2013) have highlighted that organizations may need to develop ad-hoc BDA system governance processes. In fact, such processes may improve the way managers access information to be used for decision-making. Similarly, it may allow managers to receive the right information for the right purpose. This is coherent to what was stressed by Constantiou and Kallinikos (2014), but, only when the output of BDA systems is aligned with managerial requests. Such systems can provide managers with the proper information to formulate adequate strategies.

\subsection{Purple Cluster: BDA, Dynamic Capabilities, Business Processes Management and Performance}

The fourth cluster aggregates manuscript on big data, BDA systems and business processes management. From this perspective, Sivarajah et al. (2017) reviewed BDA methodologies and their effects on production processes management. They have shown that the possibility for managers to control any aspect of production processes is related to less wastage of resources. Indeed, BDA can provide managers a large amount of data that could allow them to make more informed choices on strategies (Wu et al., 2017).

Similarly, Vera-Baquero et al. (2016) have confirmed that BDA is related with superior performance by enabling manager to better monitor any internal processes. BDA managers may be fully aware of the performance of every process, identify problems or bottlenecks, and sort-out the problem. Thus, by increasing the performance of each process, they may increase organizational performance. This topic is the talking point presented in two other manuscripts authored by Vera-Baquero et al. (2013) and Vera-Baquero et al. (2015). It has been observed that BDA systems' analytical capabilities may not be matched by traditional business process management systems, as BDA systems are capable of providing managers a more detailed information in real-time.

Superior performance is the target for the majority of managers. As stressed by Gani et al. (2014) and Kowalczyk and Buxmann (2015), BDA may influence organizational processes to identify and exploit opportunities existing in the external environment. Specifically, BDA is capable of providing managers with the insights they need to formulate the strategies need to grab and exploit every emergent opportunity. This phenomenon is related with the accuracy of the real-time insights that may be extracted from big data. Nowadays, the perceptions and the ideas of consumers are no more a hidden treasure that managers should look after, they are frequently freely available in the internet and, with the right tools, it may possible to analyse them. These insights may be diffused within the organization by the alignment between BDA systems and processes with knowledge management tools. As a consequence, strategic managerial decisions may now be supported by accurate information leading to increase in performance of organization by reducing costs or increasing revenues.

Nguyen and Cao (2015) have studied the ways in which BDA adoption may lead to stronger collaborations between partners belonging to the same production chain. The architecture of BDA systems may incentivise the sharing of data concerning production process efficiency between partners. In fact, BDA systems may also make communication processes occurring between partners more efficient.

Finally, Chae (2015) has proposed how the analysis of posts from social media can help organizations to better monitor demand trends. Thus, BDA systems may also affect demand forecasting processes.

\subsection{Discussion of the Systematic Literature Review and Possible Research Gaps}

The findings of the systematic literature review highlighted the importance of BDA for modern businesses. The possibility to apply advanced informatic and statistical analysis method is 
actually fundamental to make sense of big data and decodify their contents (Kache and Seuring, 2017).

In detail, results from the systematic literature review stressed out how BDA systems, tied up with organization-wide BDA capabilities to properly use them, matter to extract knowledge from datasets complex as big data (Dubey et al., 2018). Similarly, BDA systems may transmit information to interested players present within the firm. Hence, BDA systems may increase the quality and the speed of knowledge flows spanning the organization.

As a consequence, BDA systems and capabilities have proven fundamental to make managers obtain dramatically more information than before, particularly to what concerns any process occurring within the business and the supply chain (Mishra et al., 2018). BDA systems and capabilities may therefore allow managers to better decide about any future path the organization will have to follow.

In addition, why extant research used dynamic capabilities as the main theoretical approach emerged too. Indeed, modern organization to fully leverage BDA systems need to accept them, and need organization-wide capabilities allowing the organization to dynamically use existing systems for different scopes and with different kind of data (Ferraris et al., 2018).

To what concern theoretical findings of our research, several interesting topics emerged too. Specifically, firstly (as it is possible to see in figure 1) it is possible to observe how clusters are extremely close each other. This may be related to the very close topics described in the considered manuscripts. Actually, the most of the considered manuscripts deal with the effect of BDA on manufacturing and supply-chain, thus they share many common references. Second, apart from few exceptions such as the manuscripts from Erevelles et al. (2016) and Martin et al. (2017), it is possible to assess that the most of research on big data and marketing, marketing management and marketing management scantly use dynamic capabilities as a theoretical approach. In fact, very few manuscripts dealing with big data and marketing are present in our clusters. Third, our analysis revealed how very scant attention is usually paid to two very important points. On the one hand, research has paid scant attention to factors fostering or hampering the adoption of BDA systems in modern organizations. On the other hand, very few attentions have been paid to the need for modern business to digitally transform to fully leverage BDA systems. Finally, there is a need to better explore additional potential effects of BDA systems and capabilities such as increased innovativeness or increased absorption capabilities. As both these topics may be explored using dynamic capabilities, such an absence is significant.

Moving from this, the authors are also able to briefly suggest forward-thinking avenues for future research and possible gaps. Specifically, future researchers should try to explore, using dynamic capabilities:

1) The relationship between BDA systems and capabilities and dynamic marketing strategies;

2) Organizational characteristics or organization-related factors that may hamper or prevent the adoption of BDA in modern organizations;

3) How organization may need to digitally transform to fully leverage BDA;

4) The effects of BDA on organizations structures;

5) Which are the additional effects of BDA analytics apart from better performances.

Apart from that, the authors observed that scholars should try to develop frameworks capable of reassuming the studied phenomenon. Additionally, as the majority of the research is theoretical or qualitative, quantitative research on the phenomenon is needed.

Moving from the aforementioned suggestions, we suggest managerial scholars wishing to contributes to this stream of literature to try also to collaborate with scholars operating in different disciplines, such as informatics, or practitioners. In fact, cross-collaboration may be helpful to provide different or unexpected insights on BDA systems and capabilities. 


\section{Discussions and Conclusions}

By identifying and reviewing the most influential manuscripts, the authors have systematised existing knowledge on big data and dynamic capabilities. This is the main theoretical contribution of this research. The authors have reconfirmed that four clusters exist in the research on dynamic capabilities (Wamba and Mishra, 2017).

From a practitioner-oriented standpoint, it is possible to conclude that managers should always monitor the alignment between big data capabilities and their expectations concerning BDA systems implementation (Akter et al., 2016). In fact, whether or not big data capabilities and organizational objectives are aligned, managers may find themselves without the insight they may need to develop new strategies.

In spite of these results, our manuscript is limited to a very narrow stream of research, and future research should therefore try to definitively systematise the position of the selected stream of research within a broader field.

\section{References}

Acharya, A., Singh, S.K., Pereira, V., and Singh, P. (2018), "Big data, knowledge co-creation and decision making in fashion industry", International Journal of Information Management, Vol.42, pp.90-101.

Al Nuaimi, E., Al Neyadi, H., Mohamed, N., and Al-Jaroodi, J. (2015), “Applications of big data to smart cities", Journal of Internet Services and Applications, Vol.6, No.1, pp.125.

Akter, S., Wamba, S.F., Gunasekaran, A., Dubey, R., and Childe, S.J. (2016), "How to improve firm performance using big data analytics capability and business strategy alignment?", International Journal of Production Economics, Vol.182, pp.113-131.

Braganza, A., Brooks, L., Nepelski, D., Ali, M., and Moro, R. (2017), "Resource management in big data initiatives: Processes and dynamic capabilities", Journal of Business Research, Vol.70, pp.328-337.

Bianchi, M., Marzi, G., \& Guerini, M. (2018). Agile, Stage-Gate and their combination: Exploring how they relate to performance in software development. Journal of Business Research.

Bresciani, S., Ferraris, A., and Del Giudice, M. (2017), "The management of organizational ambidexterity through alliances in a new context of analysis: Internet of Things (IoT) smart city projects", Technological Forecasting and Social Change. DOI: https://doi.org/10.1016/j.techfore.2017.03.002

Chae, B.K. (2015), "Big data and IT-enabled services: ecosystem and coevolution", IT Professional, Vol.2, pp.20-25.

Caputo, A., Marzi, G., \& Pellegrini, M. M. (2016). "The internet of things in manufacturing innovation processes: development and application of a conceptual framework". Business Process Management Journal, 22(2), 383-402.

Caputo, A., Marzi, G., Pellegrini, M.M., and Rialti, R. (2018), "Conflict Management in Family Businesses: A Bibliometric Analysis and Systematic Literature Review", International Journal of Conflict Management. DOI: 10.1108/IJCMA-02-2018-0027

Chaffin, D., Heidl, R., Hollenbeck, J.R., Howe, M., Yu, A., Voorhees, C., and Calantone, R. (2017), "The promise and perils of wearable sensors in organizational research", Organizational Research Methods, Vol.20, No.1, pp.3-31. 
Chen, H., Chiang, R.H.L., and Storey, V.C. (2012), "Business Intelligence and Analytics: From Big Data to Big Impact", MIS Quarterly, Vol.36, No.4, pp.1165-1188.

Chen, J., Chen, Y., Du, X., Li, C., Lu, J., Zhao, S., and Zhou, X. (2013), "Big data challenge: a data management perspective", Frontiers of Computer Science, Vol.7, No.2, pp.157164.

Chen, M., Mao, S., and Liu, Y. (2014), "Big data: A survey", Mobile networks and applications, Vol.19, No.2, pp.171-209.

Chen, D.Q., Preston, D.S., and Swink, M. (2015), "How the use of big data analytics affects value creation in supply chain management", Journal of Management Information Systems, Vol.32, No.4, pp.4-39.

Contractor, F., Yang, Y., and Gaur, A. S. (2016), "Firm-specific intangible assets and subsidiary profitability: The moderating role of distance, ownership strategy and subsidiary experience", Journal of World Business, Vol.51, No.6, pp.950-964.

Côrte-Real, N., Oliveira, T., and Ruivo, P. (2017), “Assessing business value of Big Data Analytics in European firms", Journal of Business Research, Vol.70, pp.379-390.

Del Giudice, M. (2016), "Discovering the Internet of Things (IoT) within the business process management: A literature review on technological revitalization", Business Process Management Journal, Vol.22, No.2, pp.263-270.

Dobrzykowski, D.D., Leuschner, R., Hong, P.C., and Roh, J.J. (2015), "Examining absorptive capacity in supply chains: Linking responsive strategy and firm performance", Journal of Supply Chain Management, Vol.51, No.4, pp.3-28.

Dubey, R., Gunasekaran, A., and Childe, S. J. (2018), "Big data analytics capability in supply chain agility: The moderating effect of organizational flexibility", Management Decision, DOI: https://doi.org/10.1108/MD-01-2018-0119

Eisenhardt, K.M., and Martin, J.A. (2000), “Dynamic capabilities: what are they?”, Strategic Management Journal, Vol.21, No.11, pp.1105-1121.

El-Kassar, A.N., and Singh, S.K. (2018), "Green innovation and organizational performance: the influence of big data and the moderating role of management commitment and HR practices", Technological Forecasting and Social Change, DOI: https://doi.org/10.1016/j.techfore.2017.12.016

Erevelles, S., Fukawa, N., and Swayne, L. (2016), "Big Data consumer analytics and the transformation of marketing", Journal of Business Research, Vol.69, No.2, pp.897-904.

Falagas, M.E., Pitsouni, E.I., Malietzis, G.A. and Pappas, G. (2008), "Comparison of PubMed, Scopus, web of science, and google scholar: strengths and weaknesses", The FASEB Journal, Vol.22 No.2, pp.338-342.

Fawcett, S.E., and Waller, M.A. (2014), "Supply chain game changers-mega, nano, and virtual trends - and forces that impede supply chain design (ie, building a winning team)", Journal of Business Logistics, Vol.35, No.3, pp.157-164.

Ferraris, A., Mazzoleni, A., Devalle, A., and Couturier, J. (2018), "Big data analytics capabilities and knowledge management: impact on firm performance", Management Decision, DOI: https://doi.org/10.1108/MD-07-2018-0825

Frisk, J. E., and Bannister, F. (2017), "Improving the use of analytics and big data by changing the decision-making culture: A design approach", Management Decision, Vol.55, No.10, pp.2074-2088.

Fuchs, M., Höpken, W., and Lexhagen, M. (2014), "Big data analytics for knowledge generation in tourism destinations-A case from Sweden", Journal of Destination Marketing \& Management, Vol.3, No.4, pp.198-209.

Gandomi, A., and Haider, M. (2015), "Beyond the hype: Big data concepts, methods, and analytics", International Journal of Information Management, Vol.35, No.2, pp.137144. 
Gani, A., Siddiqa, A., Shamshirband, S., and Hanum, F. (2016), "A survey on indexing techniques for big data: taxonomy and performance evaluation", Knowledge and Information Systems, Vol.46, No.2, pp.241-284.

Gaur, A.S., Kumar, V., and Singh, D. (2014), "Institutions, resources, and internationalization of emerging economy firms", Journal of World Business, Vol.49, No.1, pp.12-20.

Gaur, A., and Kumar, M. (2018), "A systematic approach to conducting review studies: An assessment of content analysis in 25years of IB research", Journal of World Business, Vol.53, No.2, pp.280-289.

Gunasekaran, A., Yusuf, Y.Y., Adeleye, E.O., and Papadopoulos, T. (2018), "Agile manufacturing practices: the role of big data and business analytics with multiple case studies", International Journal of Production Research, Vol.56, No.1-2, pp.385-397.

Hazen, B.T., Boone, C.A., Ezell, J.D., and Jones-Farmer, L.A. (2014), "Data quality for data science, predictive analytics, and big data in supply chain management: An introduction to the problem and suggestions for research and applications", International Journal of Production Economics, Vol.154, pp.72-80.

Hwang, P., and Gaur, A. S. (2009), "Organizational efficiency, firm capabilities, and economic organization of MNEs", Multinational Business Review, Vol.17, No.3, pp.143-162.

Kache, F., and Seuring, S. (2017), "Challenges and opportunities of digital information at the intersection of Big Data Analytics and supply chain management", International Journal of Operations \& Production Management, Vol.37, No.1, pp.10-36.

Khan, Z. and Vorley, T. (2017), "Big data text analytics: an enabler of knowledge management", Journal of Knowledge Management, Vol.21, No.1, pp.18-34.

Kowalczyk, M., and Buxmann, P. (2015), "An ambidextrous perspective on business intelligence and analytics support in decision processes: Insights from a multiple case study", Decision Support Systems, Vol.80, pp.1-13.

Kwon, O., and Sim, J.M. (2013), "Effects of data set features on the performances of classification algorithms", Expert Systems with Applications, Vol.40, No.5, pp.18471857.

Kwon, O., Lee, N., and Shin, B. (2014), "Data quality management, data usage experience and acquisition intention of big data analytics", International Journal of Information Management, Vol.34, No.3, pp.387-394.

Labrinidis, A., and Jagadish, H.V. (2012), "Challenges and opportunities with big data", Proceedings of the VLDB Endowment, Vol.5, No.12, pp.2032-2033.

LaValle, S., Lesser, E., Shockley, R., Hopkins, M. S., \& Kruschwitz, N. (2011), "Big data, analytics and the path from insights to value", MIT Sloan Management Review, 52(2), 21.

Lavertu, S. (2016), "We all need help: "Big data" and the mismeasure of public administration", Public Administration Review, Vol.76, No.6, pp.864-872.

Lee, I. (2017), "Big data: Dimensions, evolution, impacts, and challenges", Business Horizons, Vol.60, No.3, pp.293-303.

Li, X., Song, J., and Huang, B. (2016), “A scientific workflow management system architecture and its scheduling based on cloud service platform for manufacturing big data analytics", The International Journal of Advanced Manufacturing Technology, Vol.84, No.1-4, pp.119-131.

McAfee, A. and Brynjolfsson, E. (2012), "Big Data: The Management Revolution”, Harvard Business Review, Vol.90, No.10, pp.60-68.

Manyika, J., Chui, M., Brown, B., Bughin, J., Dobbs, R., Roxburgh, C., and Byers, A. H. (201 1), "Big Data: The Next Frontier for Innovation, Competition, and Productivity", McKinsey

Global

Institute 
(http://www.mckinsey.com/insights/mgi/research/technology_and_innovation/big_dat a the next_frontier_for_innovation ). Accessed June 4th, 2018.

Martin, K.D., Borah, A., and Palmatier, R.W. (2017), "Data privacy: Effects on customer and firm performance", Journal of Marketing, Vol.81, No.1, pp.36-58.

Marzi, G., Dabić, M., Daim, T., \& Garces, E. (2017). Product and process innovation in manufacturing firms: a 30-year bibliometric analysis. Scientometrics, 113(2), 673-704.

Marzi, G., Rialti, R., Marina, D., and Caputo, A. (2018), "A mixed methods bibliometric investigation of the World Review of Entrepreneurship, Management and Sustainable Development: from qualitative to quantitative data", World Review of Entrepreneurship, Management and Sustainable Development. Link: http://www.inderscience.com/info/ingeneral/forthcoming.php?jcode=wremsd

Marzi, G., Caputo, A., \& Dabic, M. (2017). Management lessons from Italy: A bibliometric analysis of top Italian based scholars and studies published from 1985 to 2015. International Journal of Critical Accounting, 9(4), 269-288.

Marzi, G., Caputo, A., Garces, E., \& Dabić, M. (2018). A three decade mixed-method bibliometric investigation of the IEEE transactions on engineering management. IEEE Transactions on Engineering Management.

Marzi, G., Zollo, L., Boccardi, A., \& Ciappei, C. (2018). Additive manufacturing in SMEs: empirical evidences from Italy. International Journal of Innovation and Technology Management, 15(01), 1850007.

Mishra, D., Luo, Z., Jiang, S., Papadopoulos, T., and Dubey, R. (2017), “A bibliographic study on big data: concepts, trends and challenges", Business Process Management Journal, Vol.23, No.3, pp.555-573.

Mishra, D., Luo, Z., Hazen, B., Hassini, E., and Foropon, C. (2018), "Organizational capabilities that enable big data and predictive analytics diffusion and organizational performance: A resource-based perspective", Management Decision, DOI: https://doi.org/10.1108/MD-03-2018-0324

Nguyen, H. T. H., and Cao, J. (2015), "Trustworthy answers for top-k queries on uncertain Big Data in decision making", Information Sciences, Vol.318, pp.73-90.

Nuruzzaman, N., Gaur, A.S., and Sambharya, R.B. (2018), "A microfoundations approach to studying innovation in multinational subsidiaries", Global Strategy Journal. DOI: https://doi.org/10.1002/gsj.1202

Opresnik, D., and Taisch, M. (2015), "The value of big data in servitization", International Journal of Production Economics, Vol.165, pp.174-184.

Papadopoulos, T., Gunasekaran, A., Dubey, R., Altay, N., Childe, S.J., and Wamba, S.F. (2017), "The role of Big Data in explaining disaster resilience in supply chains for sustainability", Journal of Cleaner Production, Vol.142, pp.1108-1118.

Popli, M., Ladkani, R.M., and Gaur, A. S. (2017), "Business group affiliation and postacquisition performance: An extended resource-based view", Journal of Business Research, Vol.81, pp.21-30.

Prescott, M. (2014), "Big data and competitive advantage at Nielsen", Management Decision, Vol.52, No.3, pp.573-601.

Rialti, R., Marzi, G., Silic, M., and Ciappei, C. (2018), “Ambidextrous organization and agility in big data era: the role of business process management systems", Business Process Management Journal. DOI: https://doi.org/10.1108/BPMJ-07-2017-021

Sassetti, S., Marzi, G., Cavaliere, V., \& Ciappei, C. (2018). Entrepreneurial cognition and socially situated approach: a systematic and bibliometric analysis. Scientometrics, 116(3), 1675-1718. 
Sivarajah, U., Kamal, M. M., Irani, Z., and Weerakkody, V. (2017), "Critical analysis of Big Data challenges and analytical methods", Journal of Business Research, Vol.70, pp. 263-286.

Tallon, P.P., Ramirez, R.V., and Short, J.E. (2013), "The information artifact in IT governance: toward a theory of information governance", Journal of Management Information Systems, Vol.30, No.3, pp.141-178.

Teece, D.J. (2009), Dynamic Capabilities and Strategic Management: Organizing for Innovation and Growth, Oxford University Press: Oxford (UK).

Teece, D. J., Pisano, G., and Shuen, A. (1997), "Dynamic capabilities and strategic management", Strategic Management Journal, Vol.18, No.7, pp.509-533.

Tirunillai, S., and Tellis, G. J. (2014), "Mining marketing meaning from online chatter: Strategic brand analysis of big data using latent dirichlet allocation", Journal of Marketing Research, Vol.51, No.4, pp.463-479.

Tranfield, D., Denyer, D., and Smart, P. (2003), “Towards a methodology for developing evidence-informed management knowledge by means of systematic review", British Journal of Management, Vol.14, No.3, pp.207-222.

Van Eck, N.J. and Waltman, L. (2010), "Software Survey: Vosviewer, A Computer Program for Bibliometric Mapping”, Scientometrics, Vol.84, No.2, pp.523-538.

Vera-Baquero, A., Colomo-Palacios, R., and Molloy, O. (2013), "Business process analytics using a big data approach", IT Professional, Vol.15, No.6, pp.29-35.

Vera-Baquero, A., Colomo-Palacios, R., and Molloy, O. (2016), "Real-time business activity monitoring and analysis of process performance on big-data domains", Telematics and Informatics, Vol.33, No.3, pp.793-807.

Vera-Baquero, A., Colomo Palacios, R., Stantchev, V., and Molloy, O. (2015), "Leveraging big-data for business process analytics”, The Learning Organization, Vol.22, No.4, pp215-228.

Vlajčić, D., Caputo, A., Marzi, G., \& Dabić, M. (2019). Expatriates managers' cultural intelligence as promoter of knowledge transfer in multinational companies. Journal of Business Research, 94, 367-377.

Wamba, S.F., and Mishra, D. (2017), "Big data integration with business processes: a literature review”, Business Process Management Journal, Vol.23, No.3, pp.477-492.

Wamba, S.F, Gunasekaran, A., Akter, S., Ren, S. J. F., Dubey, R., and Childe, S.J. (2017), "Big data analytics and firm performance: Effects of dynamic capabilities", Journal of Business Research, Vol.70, pp.356-365.

Wu, K.J., Liao, C.J., Tseng, M.L., Lim, M.K., Hu, J., and Tan, K. (2017), "Toward sustainability: using big data to explore the decisive attributes of supply chain risks and uncertainties", Journal of Cleaner Production, Vol.142, pp.663-676.

Xuemie, T. (2017), "Big data and knowledge management: a case of déjà vu or back to the future?", Journal of Knowledge Management, Vol.21, No.1, pp.113-131.

Yang, Y., Pan, B., and Song, H. (2014), "Predicting hotel demand using destination marketing organization's web traffic data", Journal of Travel Research, Vol.53, No.4, pp.433447.

Zeng, J., and Khan, Z. (2018), "Value creation through big data in emerging economies: The role of resource orchestration and entrepreneurial orientation", Management Decision, DOI: https://doi.org/10.1108/MD-05-2018-0572

Zhou, Z.H., Chawla, N.V., Jin, Y., and Williams, G.J. (2014), "Big data opportunities and challenges: Discussions from data analytics perspectives [discussion forum]", IEEE Computational Intelligence Magazine, Vol.9, No.4, pp.62-74. 
Zollo, L., Marzi, G., Boccardi, A., \& Surchi, M. (2015). How to match technological and social innovation: Insights from the biomedical 3d printing industry. International Journal of Transitions and Innovation Systems, 4(1-2), 80-95.

Tables

\begin{tabular}{|r|r|r|}
\hline Year & Number of Papers & \% Variation \\
\hline 2012 & 2 & -- \\
\hline 2013 & 7 & $+250,00 \%$ \\
\hline 2014 & 14 & $+100,00 \%$ \\
\hline 2015 & 23 & $+64,29 \%$ \\
\hline 2016 & 30 & $+30,43 \%$ \\
\hline 2017 & 94 & $+213,33 \%$ \\
\hline Total Papers & $\mathbf{1 7 0}$ & \\
\hline
\end{tabular}

Table 1 - Number of Papers among the Years

\section{Figures}

Figure 1- Manuscripts' temporal distribution 


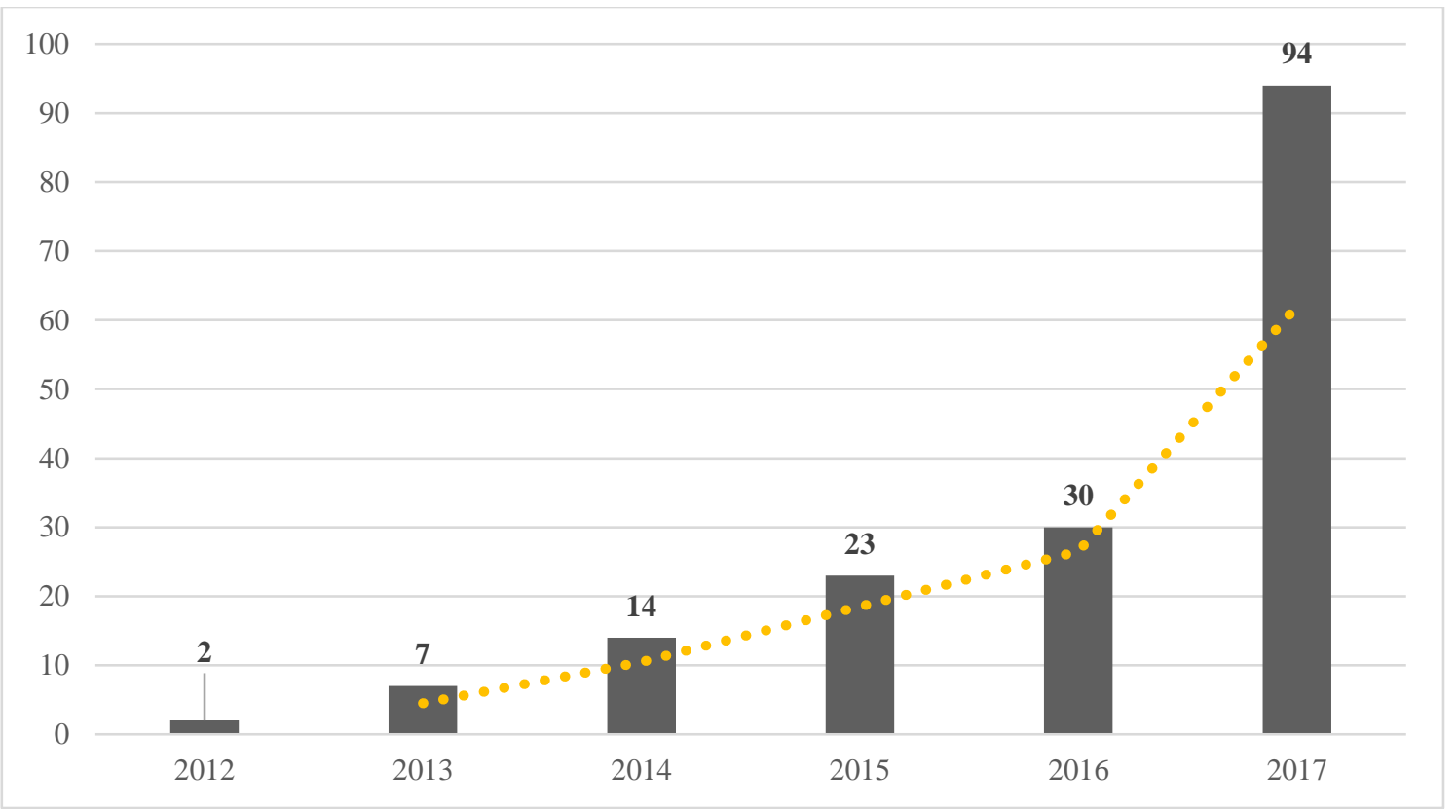

Source: Authors' elaboration 
Figure 2. VOS results

bhat (2015)

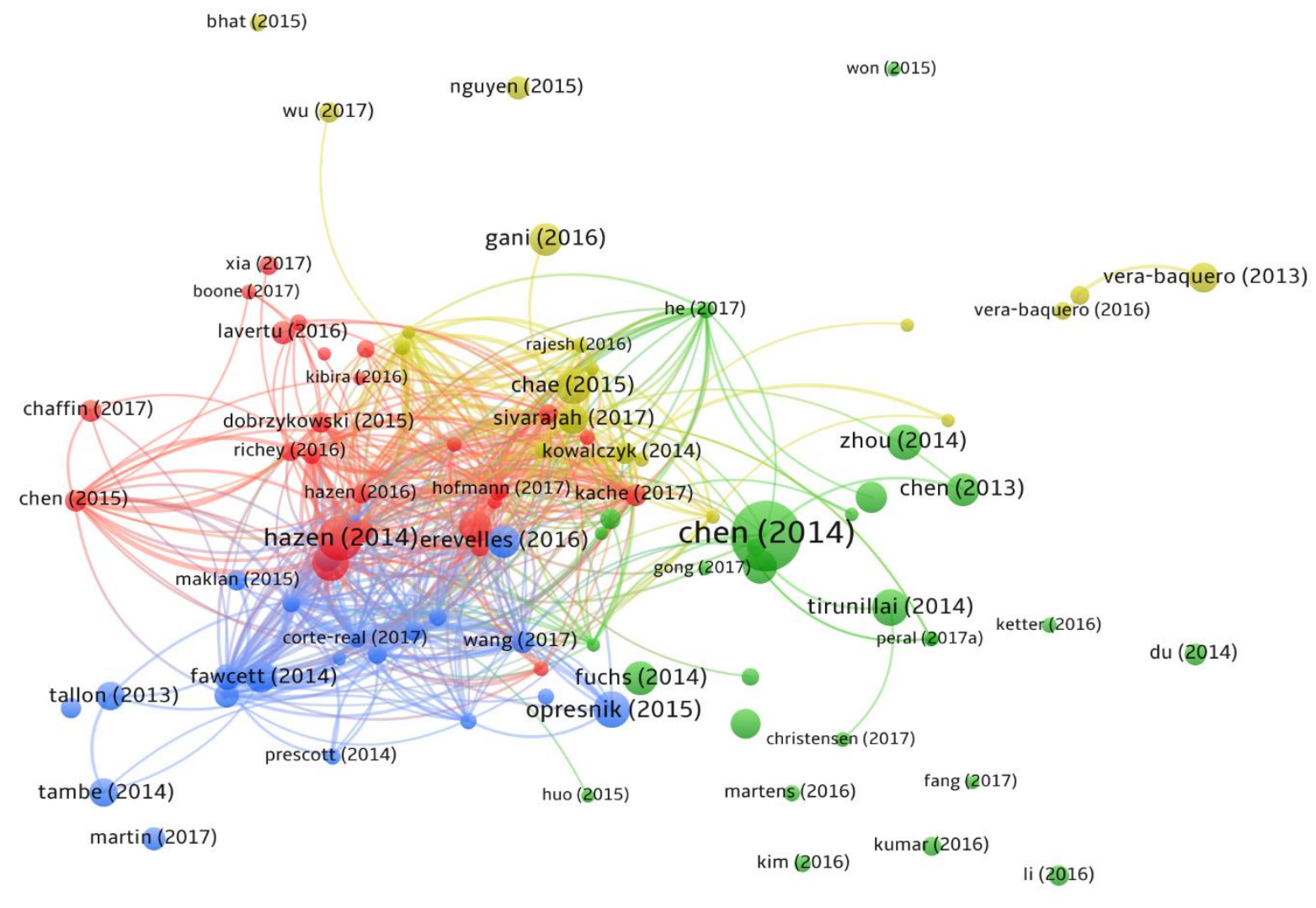

bosco (2015)

Source: Authors' elaboration created with VOS viewer 
